\title{
Causes of sudden cardiac death in Moscow
}

\author{
Y. I. Pigolkin ${ }^{1}$, M. A. Shilova ${ }^{1}$, I. V. Globa ${ }^{1}$ and Osama Mohammed AlMadani ${ }^{2 *}$
}

\begin{abstract}
Background: Sudden cardiac death (SCD) refers to unanticipated death as a consequence of cardiac failure which takes place over a brief time period (typically within an hour of the commencement of symptoms) in an individual, who may or may not be known to be subject to cardiac disease, but in whom no fatal condition has been diagnosed. The objective of this investigation was to identify the potential cause of SCD in the young population in Moscow.

Result: Analysis revealed that the mean age of the deceased amongst men was 24.6 years, and amongst women was 29.1 years. Seventy-six percent of sudden deaths were found to result from some previously undiagnosed pathology of the cardiovascular system, and cardiomyopathy is the most common cause of death in young people. Coronary heart disease is the most common cause of death in people above 40 years old.

Conclusion: Investigation to diagnose the causes of SCD constitutes a relevant, comprehensive, and multidisciplinary undertaking, which ought to be founded upon the application of novel and current diagnostic methodologies. An integrated strategy to the quest for the underlying reason for sudden death ought to be founded upon the outcomes of biochemical, anatomical, genetic, pathophysiological, and other investigations. The search and development of objective risk factors will permit timely therapeutic intervention for patients with cardiovascular pathology to minimise and prevent the risk of sudden cardiac death.
\end{abstract}

Keywords: Sudden cardiac death, Cardiomyopathy, Coronary heart disease, Connective tissue disorder, Moscow, Russian Federation

\section{Background}

Sudden cardiac death (SCD) amongst the young population represents both a clinical and social concern. Appropriate identification of risk factors with alleviation of premorbid conditions represents key goals for the medical professionals investigating the mechanisms and underlying reasons for SCD, via biochemical and pathomorphological approaches [Doolan et al., 2004, Gorizontov et al., 1983].

SCD within those younger than 35 years of age generally gives rise to controversial questions amongst physiologists, doctors, and those in the legal profession. The primary factor leading to death in patients over 60 is known to be coronary artery obturating thrombosis [Vnezapnayasmert', 1982; Dietz, 1967]. With respect to young individuals, SCD is thought to be the consequence of hypoxic damage to the myocardium as a result of stress and excessive catecholamine secretion [Doolan et al., 2004, Gorizontov et al., 1983]. The World

\footnotetext{
* Correspondence: mkharoshah94@gmail.com

${ }^{2}$ Forensic Medicine Center in Dammam, Dammam, Kingdom of Saudi Arabia Full list of author information is available at the end of the article
}

Health Organization (WHO) define SCD as a non-violent or natural death of a healthy individual, previously in a satisfactory condition, which unexpectedly takes place within $6 \mathrm{~h}$ subsequent to the commencement of acute illness.

Current diagnostic approaches, e.g., biochemical, histochemical, immunohistochemical, and molecular autopsy, are widely applied to determine underlying reasons for SCD in young people [Bokeriya et al., 2011]. However, it is also vital to establish trace element composition for evaluating the risk of SCD and the existence of congenital connective tissue disorders.

The objective of this investigation was to identify the potential cause of SCD in the young population in Moscow.

\section{Material and methods}

Instances of SCD occurring over a decade (2007-2016) in Moscow were examined and evaluated across a range of age groups: $15-39$ years, $40-59$ years, and over 60 years. Demographic, clinical, and autopsy data were collected from database files as well as detailed analysis and review of all records concerning clinical background 
Table 1 Rates for sudden death in Moscow (2005-2014)

\begin{tabular}{lllllllllll}
\hline Rates & \multicolumn{1}{l}{ Years } & \multicolumn{1}{l}{} & \multicolumn{1}{l}{} \\
\cline { 2 - 10 } & 2007 & 2008 & 2009 & 2010 & 2011 & 2012 & 2013 & 2014 & 2015 & 2016 \\
\hline Non-violent death (cases per year) & 16.519 & 16.688 & 16.390 & 17.990 & 15.263 & 17.515 & 17.792 & 17.792 & 18.075 & 16.538 \\
Deaths from cardiovascular pathology & 13.07 & 13.033 & 12.839 & 14.375 & 11.898 & 14.095 & 14.038 & 14.360 & 13.670 & 12.547 \\
$\%$ & 79.1 & 78.0 & 78.3 & 79.9 & 77.9 & 80.4 & 78.9 & 79.3 & 75.6 & 75.8 \\
\hline
\end{tabular}

and demographic details, the circumstances surrounding deaths, and autopsy findings.

\section{Results and discussion}

Table 1 highlights that the mean death rate from cardiovascular disease is $78.3 \%$ and that of this fraction, SCD is without doubt the major contributor.

Pathologists, geneticists, and other medical professionals are all interested in the sudden death of young people. The possible reasons for the death of a young person who is apparently in a good state of health, leading an active, healthy lifestyle, where obvious external factors, such as toxins, may be discounted, always arouses the interest of the medical establishment, as well as public concern. Available statistics for sudden death reveal that the mean contribution from deaths of young people is 13.5\% (Table 2).

Analysis of statistics for sudden death amongst young people also highlighted that the mean age at death for men is 24.6 years, whilst for women, it is 29.1 years.

The predisposing factor that leads to sudden death amongst young people has been identified as high physical loading, such as sports activities (e.g., physical education lessons, training sessions, sports competitions, and also the period post-training). The results demonstrate that $76 \%$ of sudden deaths are due to undiagnosed cardiovascular system pathology. Statistics for locations of death are as follows: house, apartment (36\%); places of service or military training (15\%); higher and secondary schools (7\%); sports facilities, such as gym, sports club, sports ground, and sports hall of educational institutions (28\%); other public places (14\%) (Fig. 1).

Psychoemotional stress is also a contributory factor for SCD in young people [Gorizontov et al., 1983, Pigolkin et al., 2016]. In $41 \%$ of cases, SCD was preceded by a psycho-emotional stress situation. Emotional stress can result in the activation of a sympathetic response within the heart and coronary vessels and constitutes one of the most critical predisposing factors to the development of ventricular fibrillation. Concomitantly, oxygen and energy consumption dramatically increase, and this can result in the generation of biochemical anomalies in the myocardium, such as energy depletion of cardiomyocytes with dystrophic alterations, ischaemic myocardial damage, and focal fibrosis, which produces a foundation for the development of fatal arrhythmias, when localised within the conducting pathways of the heart [Pigolkin et al., 2016, Goldstein et al., 1994, Osipov et al., 2012].

Statistics for SCD in young people reveal that cardiomyopathy is the most common cause of death (see Table 3). Whilst $76 \%$ of cases of sudden death due to cardiomyopathy in young people were recorded in 2007 , this proportion had increased to $81 \%$ in 2016 . Such findings may derive from a number of causes, including secondary lesions of the myocardium, from toxicity, endocrine factors, infectious agents, systemic connective tissue diseases or, and genetically inherited disorders.

A number of cardiovascular pathologies known to promote the risk of sudden death in young people have a hereditary component (e.g., hypertrophic cardiomyopathy and various arrhythmias). Commencement of presentation of such diseases may involve the development of a variety of cardiovascular abnormalities, both during the period of early embryogenesis and also in the juvenile period, and these may derive from either point mutations or from chromosomal abnormalities or may possess polygenic traits. Many researchers have carried out investigations examining variable genetic determinants for the generation of a variety of cardiomyopathies, in addition to the heterogeneous nature of this disease [Goldstein et al., 1994, Osipov et al., 2012].

The first gene identified is located on chromosome 14 and codes for the production of the beta-myosin heavy chain. Subsequently, mutations of nine genes involved in the generation of abnormalities of this chain were identified. These were found to code for the primary structural cardiac molecular components, including cardiac

Table 2 Sudden death rates

\begin{tabular}{|c|c|c|c|c|c|c|c|c|c|c|}
\hline & 2007 & 2008 & 2009 & 2010 & 2011 & 2012 & 2013 & 2014 & 2015 & 2016 \\
\hline Total number of sudden deaths & 16.519 & 16.688 & 16.390 & 17.990 & 15.263 & 17.515 & 17.792 & 17.792 & 18.075 & 16.538 \\
\hline Sudden death of young people & 2.485 & 2.743 & 2.429 & 2.522 & 2.279 & 2.586 & 2.325 & 2.119 & 1.772 & 1.683 \\
\hline Abs. (\%) & 15 & 16.4 & 14.8 & 14.01 & 14.9 & 14.7 & 13.06 & 12.3 & 9.8 & 10.1 \\
\hline
\end{tabular}




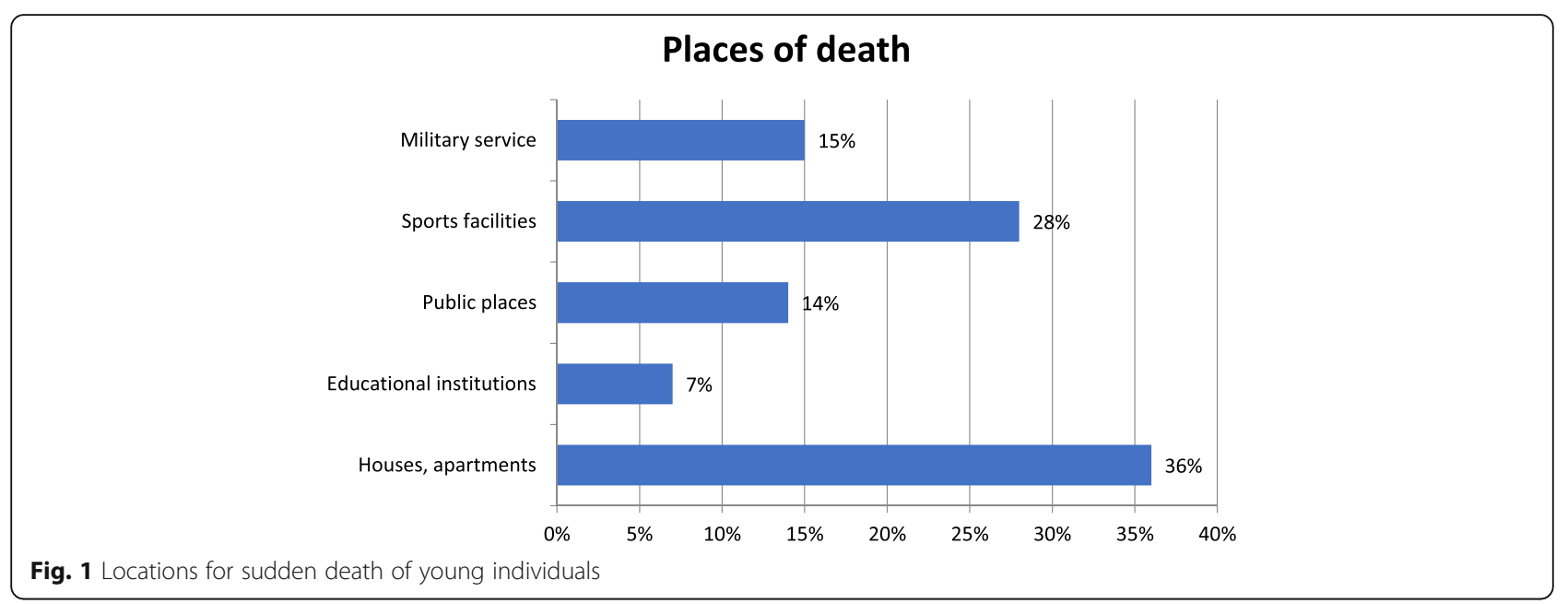

actin, troponins I and II, tropomyosin, myosin binding protein, and myosin light chains [Tester et al., 2004, Lehnart et al., 2004, Priori et al., 2000]. More recently, reports have highlighted the impact on the production of hypertrophic cardiomyopathic defects in genes coding for AMP-kinase and iduronidase in Fabry's disease. The contribution of genetic mutations in the production of abnormalities in intercellular contacts between cardiomyocytes was emphasised.

An additional pathology with a genetic foundation is the long QT interval syndrome. This disorder has been studied extensively via genetic methodologies, and consequently, it has been noted that the majority of mutations are correlated with an autosomal recessive mode of inheritance which in turn is correlated with alterations in the eight major genes encoding the structure of the potassium, sodium, and calcium ion channels of cardiomyocytes [Moolman et al., 1997 and Tester \& Ackerman, 2007].

Another pathology responsible for an increased risk of $\mathrm{SCD}$ is Brugada syndrome. Genetic experiments have verified that Brugada syndrome can be due to both monogenic and polygenic factors, which are primarily correlated with mutations in the SCN5a gene and which encode the sodium channel alpha subunit. This condition, like all

Table 3 Statistics for the causes of SCD in young people

\begin{tabular}{lll}
\hline Cause of death & 2007 & 2016 \\
\hline Cardiomyopathies (\%) & 76 & 81 \\
Myocarditis, myocardial dystrophy (\%) & 2.4 & 1.6 \\
Acute coronary insufficiency (\%) & 2.5 & 2.7 \\
Vascular pathology (\%) & 6.2 & 6.1 \\
Congenital heart diseases (\%) & 0.5 & 1.1 \\
Coronary heart disease (\%) & 9.1 & 3.8 \\
Other heart diseases (\%) & 3.3 & 3.7 \\
\hline
\end{tabular}

canalopathies, is associated with a characteristic lack of any signs of chemical or structural damage to the heart or its contractile elements, valvular apparatus, and developmental structural anomalies [Jervell and Lange-Nielsen, 1957]. Medical examination of patients presenting with this disorder indicates a dramatic alteration in the ECG, together with an increased ST segment and blockade of the right side of the bundle of His. This disorder is inherited by an autosomal dominant mode of inheritance. Whilst the risk

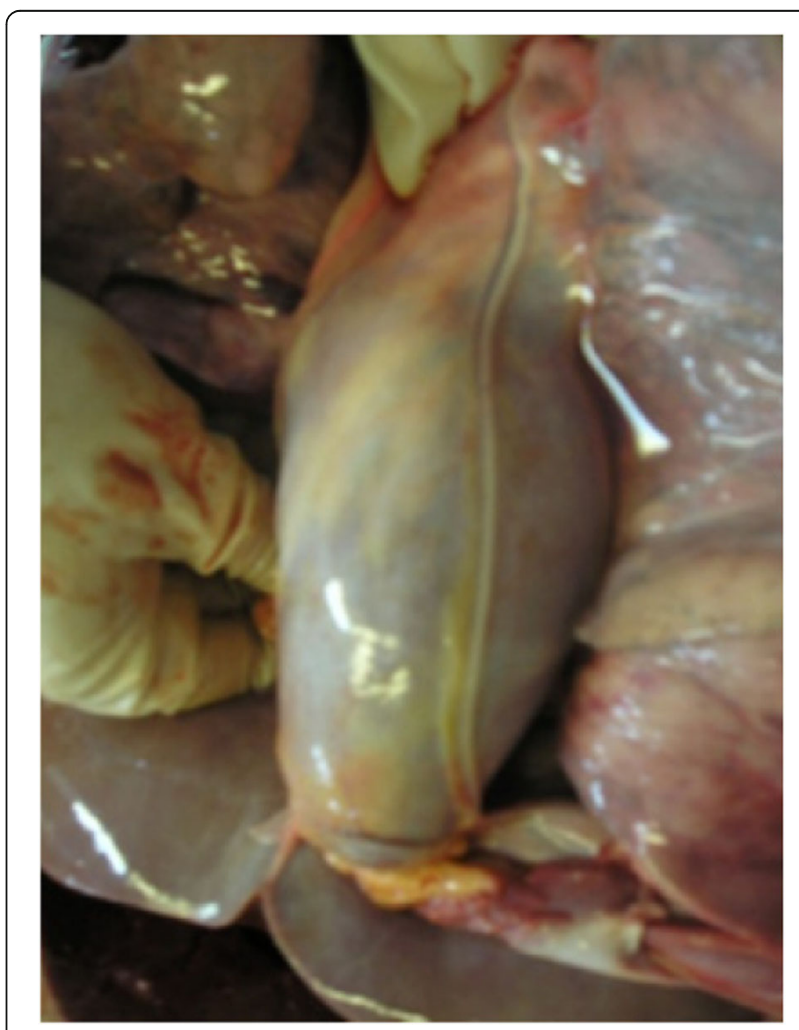

Fig. 2 'Drop-like' heart exhibiting hypoplasia due to CTD 


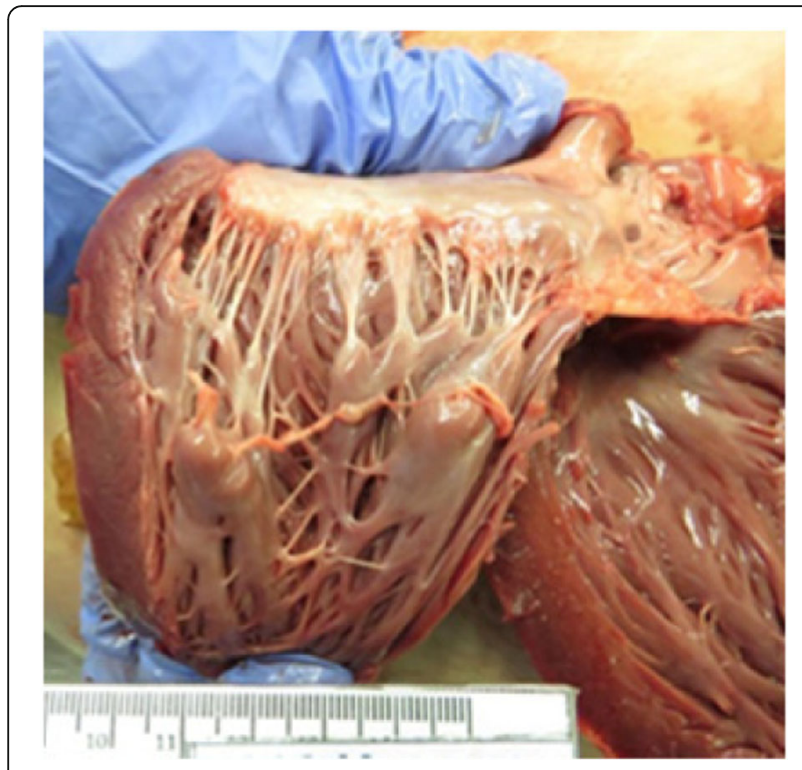

Fig. 3 Multiple apical and median anomalous chords, exhibiting basal fibrotic parietal endocardium, hypertrophy and shortening of trabecular muscles with haemorrhages from a young patient presenting with signs of CTD (connective tissue disorder)

of SCD is greatest in males between the ages of 30-40 years, a family background of fatal arrhythmias and physical stress can contribute a predisposing factor for their development of this condition. A further disorder with a genetic basis which is associated with a high risk of SCD in young individuals as a consequence of physical activity is catecholaminergic polymorphic ventricular tachycardia. This condition is known to be caused by at least two mutations in the RyR2 and casq2 genes. The former gene encodes a type 3 ryanodine receptor, which constitutes an essential protein for the regulation of calcium release from the sarcoplasmic reticulum during myocardial cell excitation and contraction. Casq2, or Calsequestrin, is associated with the regulatory proteins responsible for the sequestration of calcium ions within the sarcoplasmic reticulum. Such pathological conditions present in the form of syncopal conditions, due to severe physical or psychoemotional stress, which triggers the generation of ventricular tachycardia [Tester et al., 2004].

Results indicate that for young people, in nearly all instances, heart pathology has remained undiagnosed during life. Eighty-three to $87 \%$ of incidences of SCD amongst young people revealed both external and internal indications of congenital pathology of connective tissue and developmental abnormalities:

- Height above $182 \mathrm{~cm}$ in men, $168 \mathrm{~cm}$ in women (96\%)

- Asthenic constitution (99.7\%)

- Funnel-shaped and keeled sternal pathology (68\%)

- Deformation of the spine in the form of scoliosis, lordosis, and combined forms (77\%)

- Elongation of limbs and arachnodactyly (38\%)

- Curvature of the lower extremities, different forms of flat feet, the second digit of the foot being longer than the first

- Varicose veins

- Thin skin, existence of striae, and scar changes of the skin (keloid scars)

Musculoskeletal system pathology was seen to result in a contravention of the normal anatomical ratios within the thoracic cavity and, consequently, the development of a thoraco-diaphragmatic syndrome. For patients presenting with connective tissue disorder (CTD), development of the kyphoscoliotic heart, a drop heart, typified by hypoplasia with a predominance of vertical dimensions (Fig. 2), are characteristic features. Skeletopathies result in the anomalies positioning of the of the heart, with torsion or partial torsion, which in turn leads to haemodynamic anomalies during life. For $97 \%$ of young adults, the main mechanism at the onset of death is arrhythmia. The primary structural necessities for an arrhythmogenic death include abnormalities of heart formation with the existence of skeletal deformities, the existence of anatomical alterations in the heart, e.g., multiple abnormal chords in different cavities (apical, transverse, diagonal, median, etc.), and the existence of endocardial focal fibrosis in projections of attachment of anomalous chords and in the area of the zones of the cardiac conduction bundles, in addition to alterations in the valves (mitral valve prolapse, tricuspid regurgitation, aortic valve stenosis, etc.) (Fig. 3).

Reasons underlying death in young individuals with CTD include rupture of congenital aneurysms of blood vessels (24\%) for vessels of the brain, aorta, and coronary vessels. For $32 \%$ of incidences, the reasons underlying aneurysm generation with subsequent rupture were diagnosed syndromal varieties, including Marfan syndrome and Ehlers-Danlos syndrome. Diagnosis of such disorders is founded upon

Table 4 Sudden death rates in the over-60s age group

\begin{tabular}{|c|c|c|c|c|c|c|c|c|c|c|}
\hline & 2007 & 2008 & 2009 & 2010 & 2011 & 2012 & 2013 & 2014 & 2015 & 2016 \\
\hline Total number of incidences of sudden death & 16.519 & 16.688 & 16.390 & 17.990 & 15.263 & 17.515 & 17.792 & 18.104 & 18.075 & 16.538 \\
\hline Persons older 60 years of age, abs. & 6.902 & 6.902 & 7.366 & 8.966 & 7.189 & 9.004 & 9.689 & 10.208 & 10.709 & 9.682 \\
\hline$\%$ & 41.8 & 41.3 & 44.9 & 49.8 & 47.1 & 51.4 & 54.4 & 56.3 & 59.2 & 58.5 \\
\hline
\end{tabular}


Table 5 Gender distribution of sudden death

\begin{tabular}{lllllllllll}
\hline & 2007 & 2008 & 2009 & 2010 & 2011 & 2012 & 2013 & 2014 & 2015 & 2016 \\
\hline Men (\%) & 52.8 & 49.2 & 49.4 & 46.0 & 48.9 & 45.5 & 44.5 & 44.4 & 43.7 & 43.6 \\
$\begin{array}{l}\text { Women } \\
(\%)\end{array}$ & 41.2 & 50.8 & 50.6 & 54.0 & 51.1 & 54.5 & 55.5 & 55.6 & 56.3 & 56.4 \\
\hline
\end{tabular}

pathomorphological methodologies and molecular genetic research approaches, which are all verified by biochemical research results.

Sudden death in those over 40 years old is typified by atherosclerotic lesions in variously located cardiovascular vessels: coronary heart disease (CHD) can be seen to be responsible for $50.5 \%$ of all SCD cases. Other causes include cerebrovascular pathology (6\%) and complications of arterial hypertension (43.5\%). Causes of mortality in this age group included acute myocardial infarction (37\%), postinfarctional cardiosclerosis (44\%), indications of ischaemic or haemorrhagic cerebral infarction (7.4\%), and also decompensation of chronic cardiovascular insufficiency (11.6\%). In $84 \%$ of instances, post-mortem indications of signs of a metabolic syndrome, including the existence of arterial hypertension, type 2 diabetes, and metabolic disorders (e.g., obesity), represent the primary risk factors for SCD in the over-60s age group.

Statistics for post-mortem reports over the last decade reveal the mortality rate of the over-60s age group (elderly, old, and long-livers) (Table 4).

The gender bias within the statistics of SCD in the over-60s age group is a reflection of the predominance of females in the sample population (Table 5).

Therefore, the comparative characteristics of sudden death across all age groups revealed the following patterns (Table 6).

Alterations in trace element composition were noted in $83 \%$ of all reports on the pathology of connective tissue and the cardiovascular system, particularly when death was accompanied by the development of myocardial ischaemia and fatal arrhythmias. Lower potassium levels (61\%), magnesium $<0.53 \mathrm{mmol}$ (52\%), zinc $<11.5 \mathrm{mmol} / \mathrm{l}$ (33\%), fluorine $(6 \%)$, and selenium (11\%) were determined, as well as microelements contributing to the generation of collagen and bone mineralisation. Comparison of these elements with vital signs enabled reliable correlations with the reduction in these trace elements to

Table 6 Age characteristics of sudden death

\begin{tabular}{llll}
\hline Sex & $15-39$ years & $40-59$ years & $>60$ years \\
\hline Men (\%) & 78 & 57 & 48 \\
Women (\%) & 22 & 43 & 52 \\
\hline
\end{tabular}

be observed [Peacock et al., 2010, McVea et al., 2000, Visioli and Hagen, 2007].

\section{Conclusions}

Investigation to diagnose the causes of SCD constitutes a relevant, comprehensive, and multidisciplinary undertaking, which ought to be founded upon the application of novel and current diagnostic methodologies. An integrated strategy to the quest for the underlying reason for sudden death ought to be founded upon the outcomes of biochemical, anatomical, genetic, pathophysiological, and other investigations. The search and development of objective risk factors will permit timely therapeutic intervention for patients with cardiovascular pathology to minimise and prevent the risk of sudden cardiac death.

\section{Abbreviations \\ CHD: Coronary heart disease; CTD: Connective tissue disorder; SCD: Sudden} cardiac death

\section{Acknowledgements}

No specific acknowledgement.

Funding

No funding sources.

Availability of data and materials

All data regarding the article have been presented in the manuscript. There are no additional data.

\section{Authors' contributions}

All authors contributed in the data collection, manuscript writing, quality review, and data synthesis. All authors read and approved the final manuscript.

\section{Ethics approval and consent to participate}

Ethical no approval was obtained from Department of Forensic Medicine Federal State Autonomous Educational Institution of Higher Education I.M. Sechenov First Moscow State Medical University of the Ministry of Health of the Russian Federation., Moscow, Russia, 119,991.

Consent for publication

Not applicable since no participants have been involved.

\section{Competing interests}

The authors declare that they have no competing interests.

\section{Publisher's Note}

Springer Nature remains neutral with regard to jurisdictional claims in published maps and institutional affiliations.

\section{Author details}

${ }^{1}$ Department of Forensic Medicine, Federal State Autonomous Educational Institution of Higher Education I.M. Sechenov First Moscow State Medical University of the Ministry of Health of the Russian Federation (Sechenov University), Moscow, Russia119991. Forensic Medicine Center in Dammam, Dammam, Kingdom of Saudi Arabia.

Received: 13 December 2018 Accepted: 12 February 2019 Published online: 28 February 2019

\section{References}

Bokeriya LA, Revishvili AS, Neminushchij NM (2011) Vnezapnayaserdechnayasmert' M.: GEHOTAR-Media 
Dietz G (1967) GerichteMedizinfürJuristen, Kriminalisten, Studierende der Rechtwissenschaften und Medizin - vierte, vermehrteAuflage. J.A.Barth, Leipzig

Doolan A, Langlois N, Semsarian C (2004) Causes of sudden cardiac death in young Australians. Med J Aust 180(3):110

Goldstein S, Bayes-de-Luna A, Gumdo-Soldevila J (1994) Sudden cardiac death. Futura, Armonk

Gorizontov PD, Belousova OI, Fedotova MI (1983) Stress isistemakrovi. M.

Jervell A, Lange-Nielsen F (1957) Congenital deaf-mutism, functional heart disease with prolongation of the QT interval, and sudden death. Am Heart J 54(1):59-68

Lehnart SE, Wehrens XH, Laitinen PJ, Reiken SR, Deng SX, Cheng Z, Marks AR (2004) Sudden death in familial polymorphic ventricular tachycardia associated with calcium release channel (ryanodine receptor) leak. Circulation. 109(25):3208-3214

McVea KL, Turner PD, Peppler DK (2000) The role of breastfeeding in sudden infant death syndrome. J Hum Lact 16:13-20

Moolman JC, Corfield VA, Posen B, Ngumbela K, Seidman C, Brink PA, Watkins H (1997) Sudden death due to troponin T mutations. J Am Coll Cardiol 29(3):549-555

Osipov AG, Silkin SB, Pravdina EA et al (2012) Risk factors and relative coronary risk in young people. Cardiovasc Ther Prev 1:41-42

Peacock JM et al (2010) Serum magnesium and risk of sudden cardiac death in the Atherosclerosis Risk in Communities (ARIC) Study. Am Heart J 160:464-470

Pigolkin Yl, Shilova MA, Kil'dyushov EM, Gal'chikov YI (2016) Forensic medical characteristic of the causes behind sudden death in the young subjects. Sud Med Ekspert 59(5):4-9 https://doi.org/10.17116/sudmed20165954-9

Priori SG, Napolitano C, Giordano U, Collisani G, Memmi M (2000) Brugada syndrome and sudden cardiac death in children. Lancet 355(9206):808-809

Tester DJ, Ackerman MJ (2007) Postmortem long QT syndrome genetic testing for sudden unexplained death in the young. J Am Coll Cardiol 49(2):240-246

Tester DJ, Spoon DB, Valdivia HH, Makielski JC, Ackerman MJ (2004) Targeted mutational analysis of the RyR2-encoded cardiac ryanodine receptor in sudden unexplained death: a molecular autopsy of 49 medical examiner/ coroner's cases. Mayo Clin Proc 79(11):1380-1384

Visioli F, Hagen TM (2007) Nutritional strategies for healthy cardiovascular aging: focus on micronutrients. Pharmacol Res 55(3):199-206

Vnezapnayasmert'. Materialy 2-go sovetsko-amerikanskogosimpoziuma 6-8 dekabrya 1979 g. Indiapolis (SSHA). Pod red. A. M. Viherta (SSSR) i B. Launa (SSHA). M.: Medicina, 1982

\section{Submit your manuscript to a SpringerOpen ${ }^{\circ}$ journal and benefit from:}

- Convenient online submission

- Rigorous peer review

- Open access: articles freely available online

- High visibility within the field

- Retaining the copyright to your article

Submit your next manuscript at $\boldsymbol{\nabla}$ springeropen.com 